\title{
Influence of Parenting Styles on Career Development of Youths with Intellectual Disabilities in Selected Skills Training Institutions in Zambia
}

\author{
Mathatha Viola*, Ndhlovu Daniel \\ Zambia \\ *Corresponding Author: Mathatha Viola, Zambia

\begin{abstract}
This paper discusses the influence of parenting styles on career development of youths with intellectual disabilities (IDs) in selected skills training institutions in Zambia. The phenomenological study was carried out in Kabwe, Chisamba and Ndola districts of Central and Copperbelt Provinces respectively. Purposive sampling was to select a sample of 60 respondents: parents of youths with IDs (30), youths with IDs (15) and lecturers of youths with IDs (15).Semi-structured interviews, observations and Focus Group Discussions were used to collect data. Data analysis was done thematically. The study established authoritative, authoritarian, permissive and uninvolved as types of parenting styles. The study revealed that factors such as education, occupation, SES, background, affect parenting styles. The study demonstrated that parenting styles influence career development of youths with IDs through; engaging children in family chores, interactions, support, attachment and warmth. Based on the findings, the study recommends that the government through the Ministry of Education should sensitize parents of children with IDs on the different parenting styles and their effects on their children's career development.
\end{abstract}

Keywords: Career Development, Intellectual Disability (ID), Parenting Styles

\section{INTRODUCTION}

Parenting is a complex activity that includes different behaviours that work individually or collectively to influence child development. As parents rear their children, they often wonder what their children will do when they are grown up. They wish to see their children in good paying jobs, leading independent and productive lives. For parents of youths with intellectual disabilities (IDs), the wonder is even worse. Earlier studies show that parents are one of the most important and influential elements in preparing their children for future lives (Kerka, 2004).Parents have the power and ability to shape, sustain and develop their children's career development through their parenting styles (Ceka \& Murathi, 2016) and they have a strong impact on their children's career development (Whiston \& Keller, 2008). What is puzzling is how parenting styles influence career development of youths with IDs, the gap this study sought to fill.

\subsection{Statement of the Problem}

Despite parents being facilitators of career development (Whiston\& Keller 2008) in Zambia, youths with IDs are seen unemployed (CSO, 2012). Little is known on how parenting styles influence career development of youths with IDs. Ignoring such a problem would exacerbate the unemployment rates of youths with IDs, hence the study.

\subsection{Purpose}

The purpose was to establish the influence of parenting styles on career development of youths with IDs in selected skills training institutions in Zambia.

\subsection{Research Objectives}

- To establish the types of parenting styles used by parents of youths with IDs

- To determine the factors that affect parenting styles used by parents of youths with IDs.

- To determine how parenting styles influence career development of youths with IDs. 


\subsection{Research Questions}

- What are the types of parenting styles used by parents of youths with IDs?

- What factors affect parenting styles used by parents of youths with IDs?

- How do parenting styles influence career development of youths with IDs?

\subsection{Theoretical Framework}

The Ecological Systems Theory by UrieBronfenbrenner (1999) guided the study. The theory believes that development is best understood by examining ones' context. It states that career development depends on the heterogeneity of individuals and is influenced by the context in which they live. The theory believes that a person's ability to reach their potential is dependent on the presence of real life opportunities in the environment (Roundy, 2015). It argues that individuals better adjust and are more satisfied in environments that match their attitudes, values, goals and experiences, that is, they are more satisfied when there is a fit between themselves and their environment (Schutheiss, Kress, Manzi \& Glasscock, 2001). Being congruent with one's parents on career matters reflects a fit which is likely to foster career development (Duffy \&Dik, 2009). Incongruity or lack of fit on the other hand is a potential external barrier to career development (Schutheiss, et al., 2001). The theory states that parents influence development of their children through their interactions, relationships and expectations (Duffy \& Dik, 2009). The more encouraging and nurturing the environments are, the better the child will be able to develop.

\subsection{Significance of the Study}

Findings may contribute to the knowledge gap of the significant influence of parenting styles on career development of youths with IDs. They may also reveal to policy makers and implementers on how they might help parents of youths with IDs understand the effects of different parenting styles on their children's career development.

\section{LITERATURE REVIEW}

Research worldwide shows that parenting styles influences post school outcomes of adolescents. Bukaliya and Mapuranga's (2015) study sought to unearth effects of child rearing practices on child academic performance among learners in primary schools in Marondera, Zimbabwe. The qualitative study used 30 participants (10 pupils, 25 teachers and 5 parents) purposively selected. Interviews and observations were used to generate data. The study found that the most parenting styles used were permissive and neglectful. Recommendations were that workshops and campaigns should be conducted to educate parents, teachers and learners of different parenting styles and their effects. In addition, the Ministry of Education should ensure councilors are available in schools to advise parents on child rearing practices that promote career development.Although the methodology was similar, the 2015 study focused on learners in primary schools while this study focuses on families of youths with IDs, their children (youths) and lecturers.

Rani (2014) reviewed literature on the impact of parenting styles on career development of adolescents in Tirupathi, Chitoor District, Andra Pradesh focusing on three parenting styles(Authoritative, Authoritarian and Permissive). The review indicated that parenting styles play an important role in career development of adolescents. The study concludes that when planning, parents should acknowledge the immense influence they have on their children's career development. It notes that parents can also use their roles to the advantage of their children's career development. A critique on Rani's (2014) study shows that itwas merely a review of literaturewhile the current study uses a phenomenological study design on a purposively selected sample to determine how parenting styles influence career development of youths with IDs.

Halit (2013) examined the relationship between parenting styles with career interests of students at an elite school in Setiu District, Terengganu. The study population consisted of all form four students (16 years old). The sample comprised 88 students (35 boys and 53 girls) purposively selected. Two theoretical approaches by Holland (1973) and Baumrind (1991) were used. The Self-Directed Search (SDS) was used to investigate the students' career interests and the Parental Authority Questionnaire (PAQ) by Baumrind's (1971) was used to measure parental nurturing styles. Data were analyzed using descriptive statistical analysis and Pearson correlation analysis of inferential statistics. Results showed 
a significant relationship between parenting styles with career interests. The currentphenomenological study on parents of youths with IDs in skills training institutions uses interview schedules, observations and Focus Group Discussions (FGDs) to collect data. What is of concern is how parenting styles translate into career development of youths with IDs.

Elham, Siti, Rumanya and Mansor (2012) conducted a cross-sectional study on the relationship between parenting styles and academic achievement among adolescents in Sirjan, Iran. The sample comprised 382 high school adolescents (251 females and 131 males) aged between 15-18 from selected high schools. Baumrind's (1991) Parenting Style Scale was used. Results of the study indicated that authoritative parenting style has significant correlation with academic achievement resulting in career development and post school outcomes. What is not known is how this came about and whether this would be true of families of youths with IDs using FGDs and interview schedules in Africa and Zambia in particular.

Johari, Zulikfli and Maharam (2011) conducted a survey on the effects of parenting styles on child development in Malaysia. The study used a sample of 200 intact dual-earner families, 200 children and 45 class teachers. Results indicate that authoritative parenting style has positive effects on children's behavior and school achievement. An analysis of the 2011 study indicates wasa survey conducted in a western country as opposed to the current phenomenological study which used qualitative methods in the African context.

Tziner, et al., (2012) examined the connection between interpersonal relationship between parents and their offspring and the career performance of the young generation in Netanya, Isreal. The study used sample of 280 (146 $12^{\text {th }}$ grade students and 134 university students). The study hypothesized that high quality parent off spring relationship would be associated with a similarity between parent careers, job characteristics and their children's career performance for the future careers. A positive correlation was found between parent's jobs and young people's career's preferences. The current study uses a phenomenological design to investigate how parenting style influence career development of youths with IDs.

In Zambia, the influence of parenting styles on career development of youths with IDs is not known. This is the main gap in literature that this study proposed to fill.

\section{MeThOdology}

\subsection{Research Design}

The study used the phenomenological study design (Astalin, 2013) to examine lived experiences through the description provided by the people involved or involved in the issue that being researched (Creswell 2014). The design was selected because it is best used in examining lived experiences, is normally used where there is little knowledge on a phenomenon (Donalek, 2004) andthe study relied more on qualitative methods.

\subsection{Research Sites}

The study was conducted at Chipembi Farm College, Chisamba in Central Province, Kabwe School for Continuing Education, Kabwe in Central Province and the National Vocational Rehabilitation Centre, Ndola on the Copperbelt Province where youths with IDs from across the country are offered skills training.

\subsection{Target Population, Sample Size and Sampling Procedure}

The population consisted of all parents of youths with IDs at the named sites, youths with IDs and lecturers of youths with IDs. The sample comprised sixty (60) purposively selected respondents; thirty (30) parents of youthswith IDs, fifteen (15) youths with IDs and fifteen (15) lecturers of youths with IDs.

\subsection{Research Instruments, Data Collection Procedures and Data Analysis}

The study used semi-structured interviews, observations and Focus Group Discussions (FGD) to collect lived experiences from respondents. These were deemed appropriate because interpretivist researchers favour to interact and dialogue with the studied participants (Wahyumi, 2012). Semistructured interviews were administered to all respondents. FGDs were conducted to youths only. 
Observation was employed to assess the self-esteem of youths with IDs. Triangulation was done through documentary study .Data was analyzed thematically.

\subsection{Ethical Considerations}

Consistent with Reinsk (2011), ethical considerations such as seeking permission from the university ethical committee and site authorities, respondent issues of confidentiality and other basic research conventions were taken into account. For youths with IDs, consent was sought from site authorities.

\subsection{Validity}

As a way to validate contents, the report was peer reviewed.

\section{Findings ANd Discussion}

\subsection{Types Of Parenting Styles Used By Parents Of Youths With Ids}

In light of the interviews and FGDs conducted and the literature reviewed, the study revealed that the authoritarian parenting style are used by parents of youths with IDs.

Kwalibaabafyashiabaa kalipishasaana, nabaanababo baba aba mwenso, elyo kwalibanabale keleshaabanatabasa kamanau kuliabana, nganabalya, efyobalecita, nganabaya kusu kulunangu awe. There are parents that are too harsh to their children while others are too lenient they do not care what their children do, what they eat, whether they go to school or not...(P6, female, primary education, Non-formal employment).

This finding tallies with that of Rani (2014) who found that authoritarian style is one where children are expected to follow the strict rules without question and failure to follow such rules results in punishment. These parents are high on demandingness and less on responsiveness. They make children conform to unexplained rules and the style leads to children who are obedient and proficient, but they rank lower in happiness, social competence and self-esteem. The probable explanation for use of this style is because such parents are frustrated and stressed with the presence of the disability.

A good number of respondents said parents of youths with IDs use neglectful or uninvolved parenting style. Similarly, Morin (2016) points out that this style is neither responsive nor demanding. Although parents provide basic needs, parents are neither attached nor affectionate to their children, have no time to spend with their children, are low in warmth and control, are neglecting, rejecting, emotionally unsupportive, show little interaction with children and offer no guidance (Sarwar, 2016). The possible explanation for use of this style could be due to the presence of the disabilities. As such, youths with IDs learn to provide for themselves early, are emotionally withdrawn, mature quickly, have poor relationships later, are undisciplined and perform very poor academically. There is no doubt that youths from such parents were at risk of such characteristics.

A good number of respondents mentioned authoritative parenting style.

\section{I know of authoritarian and authoritative parenting and those that do not care about their children.... (L10, female, Diploma).}

This finding mirrors that of Bukaliya and Mapuranga (2015) who found that the most known and practiced style was authoritative. This style isboth demanding and responsive and is marked by firm rules and shared decisions made in a warm and loving environment (Sarwar, 2016).Parents blend a nurturing, monitoring, accepting, supportive, forgiving approach with clear standards and expectations. The use of this style could be because parents of youths with IDs have come into terms with the disability. In turn, youths with IDs from such parents happy, assertive, capable and successful in career exploration.

Findings revealed that permissive is yet another parenting style.

Some parents are just too lenient with their children, they fail to discipline them when they do wrong. It is like they fear to offend their children...(P23, male, secondary education, Nonformal employment).

Consistently, Bukaliya and Mapuranga (2015) found that some parents of youths with with IDs use permissive style. These parents are more responsive than demanding, nontraditional, lenient, do not 
require mature behavior, allow considerable self-regulation and avoid confrontation. They are generally nurturing and communicative, often taking the status of a friend but with little or no limitsetting (Sarwar, 2016). Probably such parent are over protective because of the disability. This finding explains the youths that were undisciplined, immature and demanding.

\subsection{Factors that Affect Parenting Styles used by Parents of Youths with IDs}

The study showed that factors such as background, education, occupation, socio-economic status (SES), affect parenting styles used by parents of youths with IDs.

I feel the way parents were brought up is the way they also bring up their children.

(P14,female, Tertiary education, Formal employment).

This finding mirrors that of Child Trends (2015) which found that the way parents were raised play a huge role on their parenting styles. The possible explanation could be that the background parenting functions as an ideal guide for desirable or undesirable behaviour. This calls for the need for parents of youths with IDs to be mindful of replicating parenting styles to their children.

Bambi incitobabomba...umuntunganikapyunga, akasungaabanamukutungululwa ne cebo... (some their occupation...if one is a pastor, his parenting style will be guided by the bible). (P4, secondary education, Non-formal employment).

This finding is in line with that of Child Trends (2015) which found that parental SES have proved to play a remarkable role in predicting of parenting styles. Recent studies show that the higher the SES, the low the degree of control on children (Child Trends (2015). This is because parents of low SES mostly have low education, low status jobs resulting in low income. In turn, physical stress factors may be high. This explains why most parents of low SES tend to adopt the authoritarian style with low or without emotional sensitivity. It is equally clear from the bio data of parent of youths with IDs that most parents of youths with IDs were of low SES. This is probably because most of them had low education which in turn affected their parenting styles.

Findings revealed that education influences parenting styles of parents of youths with IDs. Banks et al., (2016) found that parents with higher education are likely to be in highly paying jobs leading to high SES and high expectations which affect their parenting styles. As such, they tend to be less controlling and are more concerned with children's emotional welfare. Low income parents are not likely to be expectant on their children equally affecting their parenting style (Child Trends, 2015).It should be noted that parents of youths with IDs who are educated likely created an environment that was intellectually stimulating environment for their children. This is because education makes parental support systematic and timely which is a 'hidden' curriculum that contributes to the betterment of children's career development. Furthermore, the level of education is related to the way in which they interact with their children.

\subsection{How Parenting Styles Influence Career Development of Youths with IDs}

In the light of interviews, observations and FGDs conducted, it was clear that parenting styles influence career development of youths with IDs through engaging youths in family chores.

As parents, we allow our child to take part in home chores, this prepares him for later life.

(F16, Non-formal employment, secondary education).

Consistently, Hans (2012) found that parental variables that influence career development include activities that parents allow children to participate in. It would be deduced that such parents of youths with IDs are authoritative. Authoritative parents influence career development of their children positively asthey engage their children in different activities both at school and home. These actions motivate youths with IDs to become more explorative, self-reliant and achievement oriented, resulting in career development. However, this engagement is more meaningful when it is accompanied with parental interest, reinforcement and support. Consistent with the ecological theory, a person's ability to reach the potential is dependent on opportunities they are availed to in the environment (Roundy, 2015).Hence, parents should identify children's interests early and engage them family chores. This will make youths obtain hands on work experience in the home environment. 
On the contrary, parenting styles influences career development of youths with IDs negatively when characterized with harshness.

Children whose parents are harsh live in fear and their development is affected. (P7, Female, tertiary education, Non-formal employment)

Likewise, Morin (2016), when parents of youths with IDs are authoritarian, they are less likely to engage their children in exploratory and challenge seeking activities. Instead they restrict their children to explore their capabilities and social interaction resulting in children's dependence on parental guidance. Such a result indicates a poor fit between the child and parents which hinders career development (Duffy \& Dik, 2009).Yet, the ecological theory believes that child's development is dependent on the opportunities provided in the environment (Roundy, 2015). Alam (2016) also states that the home is the most important institution for existence and continuance of human life and development. Hence parents of youths with IDs should create a nurturing home environment with proper reward to strengthen the desired behaviour, provision of opportunities to express its views and where children are not compelled to act according to parental desires and expectations. This calls for the need for parents to accept children's desires, encourage children to explore their possibilities and provide advice where necessary.

Parenting styles influence career development of youths with IDs through support.

When children with IDs are supported, they feel motivated to work hard to please their parents. (L13, Degree).

Consistently, Keller's (2004) multiple regression analyses report revealed that when children feel supported and loved by their parents, they have more skill in thinking about careers and the world of work than when they feel un supported and unloved. In addition, when children feel loved and supported, they have confidence in their ability to find career information and to choose a career that would be interesting and exciting to them. Children perform well academically when parents are involved and are supportive (Keller, 2004).Without parental support, children are often reluctant to pursue or even explore diverse career possibilities (Olaosebikan \& Olusakin, 2014). When parents are authoritative, they let their children make their own choices while offering orientational and instrumental support for example, writing applications for enrolling in skills training centres. Nonsupportive parents of youths with IDs like the neglectful are normally unaware of what to do, how to help or that their involvement is desired at all. This makes their children feel anxious regarding career decisions. This low involvement by parents of youths with IDs may be due to low expectations on youths with IDs. This calls for the need to educate parents of youths with IDs that regardless of their sub average intellectual functioning, youths with IDs do progress into employment (Heward \& Orlansky, 1988).

This means that parents of youths with IDs who did not avail their children to career explorations or family chores restricted experiences needed for career development. This was seemed exacerbated by the dearth of interactions between some parents of youths with IDs and their children. Without the opportunities to interact, career explorations were strained. This finding confirms that youths with IDs are still limited to a lot of career activities, hence, the need to help parents of youths with IDs to understand the importance of engaging children in family chores.

Parenting styles influence career development of youths with IDs through interactions.

It is during informal talks among others that parents of youths with IDs influence their children's career development. (M11, Masters).

Consistently, Olaosebikan and Olusakin (2014) found that parents convey their influence to children through interactions (both verbal and non-verbal).These interactions affect what youths with IDs think, say or perceive about various careers. Therefore, engaging in positive social interactions with youths and emphasizing the importance of working hard, acquiring a good education and better life is influential. Interactions influence what a child thinks about the world of work, work values and employability skills. It is obvious that the attitudes and behaviors that youths with IDs adopted towards work were as a result of what their parents said.

Although permissive parents are nurturing and communicative, they often take on the status of a friend (Morin,2016). As a result, youths with IDs become less persistent at learning tasks and 
perform poorly in school negatively affecting their career development. Similarly, Sawar (2016) notes that authoritarian parents discourage communication and make strict control of their children's behaviour. This obviously limited youths with IDs' autonomy and relationship vital for career development. This scenario calls for parents of youths with IDs to have the willingness engage in career interactions with their children.

Parenting stylesinfluence career development of youths with IDs through attachment and warmth.

When parents of youths with IDs are close to their children, relate well with them, provide for them and correct them properly, children become free and are able to learn from their parents....(P20, Female, tertiary, formal employment).

This finding mirrors that of Halit (2013) whose study found that most successful children are from families with warm relationships. Point should be taken that an ideal environment helps a youths with IDs to learn skills, attitudes and behaviour which moulds them into productive and successful persons. Hans (2012) also notes that a good quality home environment with warm relationships leads to academic achievement. An ideal environment helps youths with IDs to learn skills, attitudes and behaviour which could mould them into productive and successful persons. To enhance career development of their children, parents of youths with IDs should show their children they are proud of them. Similarly, the ecological theory used in this study believes that a nurturing and encouraging environment fosters career development (Roundy, 2015).

On the other hand, lack of intimacy and guidance affects career development of youths with IDs. Morin (2016) states that although uninvolved parents provide basic needs, they are not attached or affectionate. Therefore, to help their children develop careers, parents of youths with IDs should ensure they adopt parenting styles that help children become mature, confident, assertive, explorative. Additionally, parents should spend time with their children and this would increase the probability of being role models.

It should be noted that interactions take different forms such as encouragements, explanations or advice, warning or persuasions. In this study, through interactions, some parents pressured their children to take up certain careers.

Nibatatebananileta kuno kutiniphunzilevolima.... Namwine wake nenzekufuna kun khala kapo kola (It is my father who brought me here to train in General Agriculture. I wanted to be Police Officer). (M3,21, General Agriculture).

Similarly, Olaosebikan and Olusakin (2014) found that due to expectations, parents often push their children to earn outstanding grades or to pursue certain careers. Pressuring children to take up certain career paths against their interests affects performance and career development. This is an indication of lack of support. Consistently, the ecological theory states that this signifies a poor fit which hinders career development (Roundy, 2015).As such, to enhance career development of children, parents of youths with IDs should encourage their children to make their own career decisions. On the other hand, families may hold values that place children with disabilities lowly. Given this disposition, it can be concluded that career interactions youths with IDs received were linked to parental expectations. On the positive side high parental expectations make youths with IDs set high personal expectations which they work hard to achieve.

\section{CONCLUSiON}

The study revealed authoritative, authoritarian, permissive and uninvolved as parenting styles used by parents of youths with IDs. Factors such as; education, occupation SES and background affect parenting styles on youths with IDs. The study demonstrated that parenting styles influence career development of youths with IDs through; support, engaging children in family chores, interactions and through parental attachment and warmth.

\section{RECOMMENDATION}

On the basis of the findings, the study offers the following recommendations; parents make parents aware of positive parenting roles to play for the betterment of their children's career development. To 
Influence of Parenting Styles on Career Development of Youths with Intellectual Disabilities in Selected Skills Training Institutions in Zambia

increase post-school outcomes, there is need to further research on the influence on parenting styles on career development of youths with IDs using other methodologies.

\section{REFERENCES}

[1] Astalin, P. K. (2013). Qualitative research designs. A conceptual framework. International Journal of Social Sciences and Interdisciplinary Research. USSIR, Vol 2 (1).

[2] Baumrind, D. (1991). Effective parenting during the early adolescent transition. in P. A. Cowan \& E. M. Hetherington (Eds.) Family transitions. Advances in family research series. Hillsdale, NJ, England: Lawrence Erlbaum Associates, Inc.

[3] Bronfenbrenner, U. (1999). Ecology of the family as a context for human development. Research perspectives. Developmental Psychology, 22, 723-742.

[4] Bukaliya, R. \& Mapuranga, B. (2015). Assessing the effects of child rearing practices on the academic performance of primary school learners: a perspective from the teachers, parents, and learners. International Journal of Research in Humanities and Social Studies, Vol 2, (2), 13-25.

[5] Ceka, A. \&Murati, R. (2016). The role of parents in the education of children. Journal of Education and practice, Vol 7, (5). 61-64.

[6] Central Statistics Office (2012).2010 Census of population and housing. National Analytical Report Vol 11. Lusaka: CSO.

[7] Creswell, J. (2014).Research design: Qualitative, quantitative and mixed methods approaches. Lincoln: Sage Publishers.

[8] Donalek, J. G. (2004). Phenomenology as a qualitative research method. Urologic Nursing. Vol 24, (6), 516-517.

[9] Duffy, R. D. \& Dik, B. J. (2009). Beyond the self- external influences in the career development process.Career Development Quarterly, 58, 29-43.

[10] Elham, D. Siti, N.Y., Rumaya, B. J. \&Mansor, A.T. (2012).Relationship between parenting styles and academic achievement in Sirjan.Malaysia.

[11] Halit, A.H. (2013). The relationship between parenting style with care career interest among 16-year old students. The International Journal of Social Sciences, Vol 15. 1.

[12] Keller, B. K. (2004). Parental behaviours that influence adolescent' career development. USA: University of Washington.

[13] Keller; B. K., Whiston, S. C. (2008).The role of parental influences on young adolescents' career development.Journal of Career Assessment, 16, 198-217.

[14] Morin, A. (2016). 4 Types of parenting styles. About parenting. Retrieved from http://discipline.about. $\mathrm{com} / \mathrm{cd} / \mathrm{typ}$ es of discipline/a/Types-of-Discipline-strategy-And-Parenting-org-in.

[15] Munyingi, L. (2012). Factors affecting career choices of female students in the kenyan tertiary institutions: a case of us of international university (USIU-Africa). Kenya: University of Nairobi.

[16] Olaosebikan, O. I. \& Olusakin, A. (2014). Effects of parental influence on adolescent's career choice in Baldagry Local Government area of Lagos state, Nigeria. Journal of Research and Methods in Education. Vol 4, 44-57.

[17] Rani, S, D. (2014). Impact of parenting styles on career choices of adolescents. Journal of Education and Social Policy, vol 1, (1), 19-22.

[18] Reinsk, D. (2011). What is ethics in research and why is it important? New York: Oxford University Press.

[19] Roundy, 1. (2015). Bronfenbrenner's ecological system. Www.Citethisformcom/Topic Visited August, 2017.

[20] Schultheiss, D. E. P., Kress, H. M., Manzi, A. J., \& Glasscock, M. J. (2001). Relational influences in career development: A qualitative inquiry.Counseling Psychologist, 29(2), 214-239.

[21] Tziner, A, Loberman, G., Dekel, Z.\& Sharoni, G.(2012). The influence of the parent offspring relationship on young peoples' career performance. Revista de psicologia del Trabayo y delas, Vol 28, (2), 99-105.

[22] Wahyuni, D., (2012). The research design maze: understanding paradigms, cases, methods and methodologies. Journal of Applied Management Accounting Research, Vol. 10, No. 1, winter 2012, Pp. 69-80.

\section{AUTHORS' BIOGRAPHY}

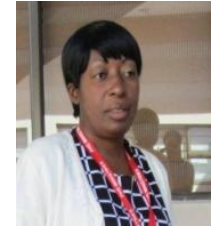

Viola Mathatha, has 25 years of teaching experience. She taught at a secondary school for 20 years before moving to Kwame Nkrumah University where she worked for 4 years. She is currently pursuing her $\mathrm{PhD}$ in Special Education with the University of Zambia. 
Dr. Daniel Ndhlovu holds a $\mathrm{PhD}$ (Special Education), has 34 years teaching experience and is formerly Assistant Dean, Post Graduate, School of Education, University of Zambia. He is currently Director, Institute of Distance Education, University of Zambia and lecturer in the School of Education, Department of Educational Psychology, Sociology and Special Education.

Citation: Mathatha Viola, Ndhlovu Daniel. "Influence of Parenting Styles on Career Development of Youths with Intellectual Disabilities in Selected Skills Training Institutions in Zambia." International Journal of Humanities Social Sciences and Education (IJHSSE), vol 5, no. 12, 2018, pp. 69-77. doi: http://dx.doi.org/ 10.20431/2349-0381.0512008.

Copyright: (C) 2018 Authors. This is an open-access article distributed under the terms of the Creative Commons Attribution License, which permits unrestricted use, distribution, and reproduction in any medium, provided the original author and source are credited. 